\title{
PERANCANGAN SISTEM BILLING PLAYSTATION BERBASIS ARDUINO ARDUINO-BASED PLAYSTATION BILLING SYSTEM DESIGN
}

\author{
Zulhipni Reno Saputra ${ }^{1}$, Toni Ismail ${ }^{2}$, Hendri Maulana $\mathbf{M}^{3}$, Hendra Pratama $\mathbf{M}^{4}$ \\ 1,2,3,4Program Studi teknologi Informasi, Universitas Muhammadiyah Palembang, Palembang \\ e-mail: zulhipni.renosaputra@um-palembang.ac.id
}

\begin{abstract}
Abstrak
Penelitian ini bertujuan untuk merancang sistem billing playstation sehingga para pelaku usaha kecil menengah dapat berperan dalam pengembangan industry 4.0. Billing playstation ini dikembangakan dengan menggunakan modul arduino yang harus deprogram terlebih dahulu, serta dikendalikan dengan menggunakan aplikasi billing playstation yang dibuat menggunakan Delphi XE8. Pada billing ini semua data disimpan dalam database mysql, sehingga dapat lebih mudah owner untuk melihat jumlah konsumen serta lamanya konsumen melakukan rental. Modul billing ini hanya memuat 8 port playstation sehingga tidak dapat ditambah lagi.
\end{abstract}

Kata kunci-Billing playstation, Arduino, Delphi

\section{Abstract}

This research aims to support the Playstation billing system so that small businesses can assist in the development of Industry 4.0. Playstation billing is developed using the arduino module which must be pre-programmed, and activated using the Playstation billing application created using Delphi XE8. On billing, all this data is stored in the mysql database, so that it can make it easier for the owner to see the number of consumers and also consumers make rent. The billing module has only 8 playstation ports so it cannot be added anymore.

Keywords —-Billing playstation, Arduino, Delphi 


\section{PENDAHULUAN}

Seiring dengan perkembangan zaman dan teknologi kebutuhan informasi yang cepat sangat di butuhkan dalam berbagai sektor kehidupan, sehingga menunjang kinerja sektor-sektor tersebut, salah satunya adalah aspek keamanan[1]. Keamanan dalam pengelolaan sistem sangat dibutuhkan sehingga dapat memaksimalkan kendala kendala yang ada, sehingga memudahkan untuk melakukan suatu pekerjaan. Bahkan hampir semua pekerjaan sudah dapat diselesaikan dengan menggunakan komputer dan berbagai aplikasinya. Perkembangan teknologi saat ini mulai bergeser kepada otomatisasi sistem kendali dengan campur tangan manusia dalam jumlah yang sangat kecil[2].

Dan saat ini Indonesia sedang giatgiatnya melakukan pengembangan industry 4.0, dan diharapkan pelaku usaha kecil menengah pun turut serta melakukan perubahan sistem. Pelaku usaha kecil menengah rental playstation dapat turut serta melakukan perubahan. Rental playtation saat ini melakukan kontrol terhadap pelaksanaan rental playstation dengan cara manual, pada saat ada konsumen melakukan penjaga rental melakukan konfigurasi di televisi sesuai jumlah jam akan merental serta mencatat nama konsumen di look book. Sistem yang berlaku ini sangat tidak efektif serta dapat merugikan pemiliknya karena bisa saja terjadi kecurangan terhadap laporannya.

Usaha kecil menengah yang transaksinya berbentuk abstrak seperti usaha warung internet atau warung Playstation mempunyai transaksi, sistem billinglah yang dibutuhkan untuk mengelolah datanya. Sistem billing adalah suatu sistem yang dapat membantu para pelaku usaha kecil menengah untuk mengatur dan mencatat segala transaksi yang terjadi. Contohnya bagi pengusaha warung rental playstation, billing sistem digunakan untuk memonitor penggunaan dan pemasukan rental playstation.

Perancangan billing playstation ini terdiri dari hardware yang dibuat dengan modul ardoino serta modul relay sedangkan secara software dibuat menggunakan Delphi dan meggunakan database sql.

\section{TINJAUAN PUSTAKA}

\subsection{Arduino}

Arduino merupakan sebuah modul elektronik atau papan rangkaian elektronik yang bersifat open source dan di dalamnya terdapat komponen utama yaitu sebuah chip mikrokontroler yang didalamnya terdapat memori dan input output, mikrokontroler yang digunakan jenis AVR dari perusahaan Atmel[1][3].

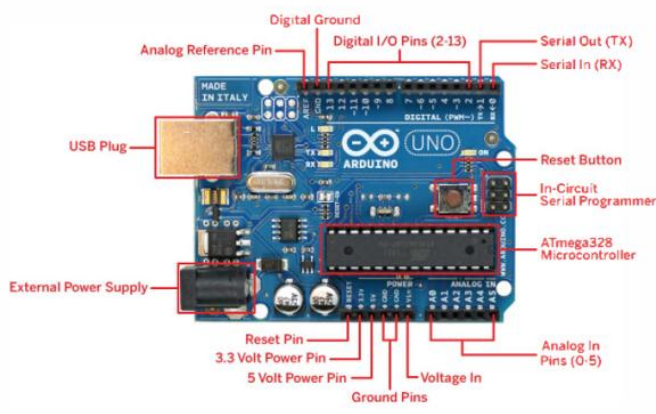

Gambar 1. Modul Arduino[4]

Komponen utama Arduino yaitu:

1. USB Plug merupakan bagian dari modul arduino yang berfungsi sebagai upload program ke mikrokontroler dan memiliki tegangan 5volts yang dapat member daya pada modul arduino.

2. Catu Daya Eksternal merupakan untuk memberi daya pada modul dan memiliki voltase yang diatur sebesar 9 hingga 12 volt.

3. Tombol Reset merupakan tombol untuk me-reset arduino ketika ditekan.

4. Mikrokontroler adalah perangkat yang menerima dan mengirim informasi atau komputer ke sirkuit masing-masing.

5. Pin Analog (O-5) adalah pin input analog dari pin AO sampai A5. 
6. Digital I / O Pins adalah input digital, pin keluaran 2 hingga 13.

7. In-Circuit Programmer adalah sumber lain untuk mengupload program, dengan menggunakan input TX dan RX.

8. Pin Ground digital dan analog

9. Pin Daya merupakan pin untuk mendapatakn tegangan sebesar 3,3 Volt dan 5 Volt.

\subsection{Module Relay}

Relay merupakan sebuah saklar yang dikendalikan dengan aliran arus listrik. Pada relay terdapat 2 bagian utama yaitu coil dan rangkaian saklar. Jadi ketika terdapat arus listrik yang mengalir pada coil selanjutnya terjadi medan magnet yang akan menarik kemudian melepas plat pada rangkaian saklar dan akan menghubungkan atau memutus arus listriknya.

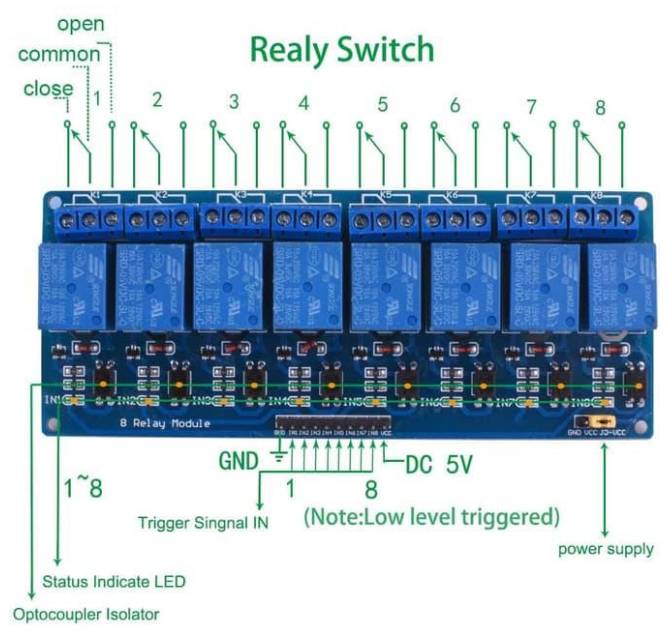

Gambar 2. Modul relay 8 Chanel[5] Komponen-komponen modul relay yaitu:

1. Relay Switch, relay switch mempunyai 3 pin yang mana berfungsi sebagai circuit normali Open dan circuit normali Close. Relay akan berkerja jika mendapatkan sinyal trigger baik bernilai 1 maupun 0 .

2. Trigger singnal in, merupakan signal pemicu untuk mengaktifkan relay switch.
3. Power supply merupakan sumber tengangan untuk mengaktifkan module Relay

4. Status indicate LED merupakan idikator untuk melihat relay yang aktif.

5. Optocoupler Isolator merupakan komponen elektronika yang berfungsi sebagai penghubung berdasarkan cahaya optik. Optocoupler terdiri dari 2 bagian utama yaitu Transmitter yang berfungsi sebagai pengirim cahaya optik dan Receiver yang berfungsi sebagai pendeteksi sumber cahaya.

6. Pin 5 Volt dan Ground

Fungsi Relay:

1. Mengendalikan rangkaian tegangan tinggi dengan menggunakan bantuan signal dari tegangan rendah.

2. Menjalankan logic function atau fungsi logika.

3. Memberikan time delay function atau fungsi penundaan waktu.

4. Melindungi motor atau komponen lainnya dari korsleting atau kelebihan tegangan.

\subsection{Delphi}

Delphi adalah sebuah Lingkungan pengembangan terpadu untuk mengembangkan aplikasi konsol, desktop, web, ataupun perangkat mobile. Produk ini pada awalnya dikembangkan oleh CodeGear sebagai divisi pengembangan perangkat lunak milik Embarcadero, divisi tersebut sebelumnya adalah milik Borland[6].

\subsection{MySql}

MySQL adalah sebuah perangkat lunak untuk pengelolaan basis data SQL (Structured Query Language) atau DBMS yang multialur, multipengguna, dengan sekitar 6 juta instalasi di seluruh dunia[7].

MySQL adalah DBMS yang open source dengan dua bentuk lisensi, yaitu Free Software (perangkat lunak bebas) dan Shareware (perangkat lunak berpemilik yang penggunaannya terbatas). Sehingga MySQL merupakan database server yang gratis dengan lisensi GNU General Public License (GPL) 
sehingga untuk keperluan pribadi atau komersil tanpa harus membayar lisensi yang ada.

\section{PERANCANGAN DAN HASIL \\ 3.1. Perancangan Hardware}

Perancangan hardware atau perangkat keras pada sistem billing playstation berupa perancangan arduino, perancangan modul relay, dan perancangan power supplay.

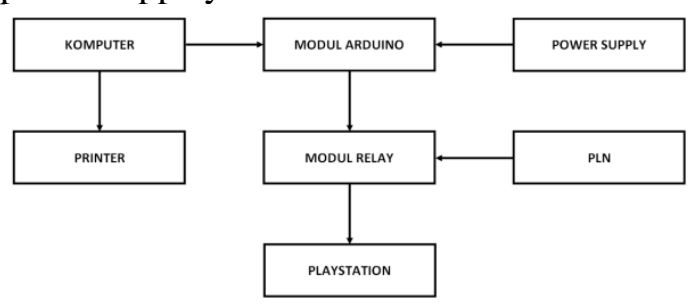

Gambar 3. Diagram Blok Billing Playstation

Diagram blok billing playstation dapat berkerja terdiri beberapa blok:

1. Modul Arduiono

Pada perancangan billing playstation digunakan modul arduino uno yang mempunyai spesifikasi sebagai berikut:

Tabel 1. Spesifikasi Arduino Uno

\begin{tabular}{|c|c|c|}
\hline No & Spesifikasi & keterangan \\
\hline 1. & $\begin{array}{l}\text { Tegangan } \\
\text { Operasi }\end{array}$ & $5 \mathrm{~V}$ \\
\hline 2. & Tegangan Input & $\begin{array}{l}\text { (disarankan) } 7- \\
12 \mathrm{~V}\end{array}$ \\
\hline 3. & $\begin{array}{l}\text { Batas Tegangan } \\
\text { Input }\end{array}$ & $6-2 \mathrm{OV}$ \\
\hline 4. & Pin Digital I/O & $\begin{array}{l}14 \text { (di mana } 6 \\
\text { pin output } \\
\text { PWM) }\end{array}$ \\
\hline 5. & Pin Analog Input & 6 \\
\hline 6. & $\begin{array}{l}\text { Arus DC per } \mathrm{I} / \mathrm{O} \\
\text { Pin }\end{array}$ & $40 \mathrm{~mA}$ \\
\hline 7. & $\begin{array}{l}\text { Arus DC untuk } \\
\text { pin }\end{array}$ & $3.3 \mathrm{~V} 50 \mathrm{~mA}$ \\
\hline 8. & Flash Memory & $\begin{array}{l}32 \mathrm{~KB} \\
\text { (ATmega328), } \\
\text { di mana } 0,5 \mathrm{~KB} \\
\text { digunakan oleh } \\
\text { bootloader }\end{array}$ \\
\hline 9. & SRAM & $\begin{array}{l}2 \mathrm{~KB} \\
\text { (Atmega328) }\end{array}$ \\
\hline 10. & EEPROM & $\begin{array}{l}1 \mathrm{~KB} \\
\text { (Atmega328) }\end{array}$ \\
\hline 11. & Clock & $16 \mathrm{MHz}$ \\
\hline
\end{tabular}

Pada modul ini yang berfungsi sebagai inputan di dapat dari output aplikasi billing playstation yang masuk ke port USB dan sebagai output ada pada port digital I/O pin, adapun pin yang digunakan yaitu pin 4 , pin 5 , pin 6 , pin 7 , pin 8 , pin 9 , pin 10 , pin 11. Masing-masing pin akan terhubung ke pin pada modul relay.

Pin akan bernilai High jika mendapatkan inputan dari aplikasi billing playstation yang sudah di deklarasikan High, dan pin akan bernilai low jika mendapat inputan dari aplikasi billing playstation yang di deklarasikan low.

\section{Modul relay}

Modul Relay ini terdiri dari 8 relay switch yang sudah dirangkai menjadi sebuah modul. Masing-masing relay akan mendapat Trigger dari modul arduino yang nantinya akan mengaktifkan relay switch sehingga tegangan dari PLN bisa mengalir dan playstation akan berfungsi.

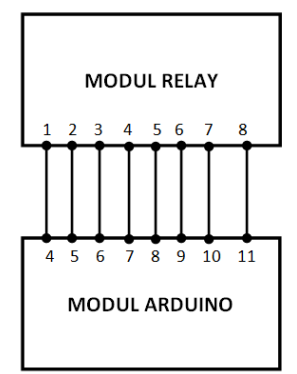

Gambar 4. Interkoneksi antara pin digital I/O di modul arduino dengan trigger signal in pada modul relay

\section{Komputer}

Komputer digunakan sebagai server billing playstaion yang berfungsi untuk mencatat serta mengendalikan modul billing playstation. Komputer dihubungkan ke modul arduino dengan menggunakan port USB.

\section{Printer}

Printer digunakan sebagai media untuk output dari sistem billing playstation. Print akan mencatat nama pengguna playstation, tanggal dan waktu bermain serta lama waktu bermain dan jumlah nominal yang harus dibayar. 


\section{Power supplay}

Power supplay merupakan hal yang penting untuk mengaktifkan modul arduino dan modul relay. Tegangan yang di supplay untuk modul arduino sebesar 12 volt begitu juga untuk modul relay.

\subsection{Perancangan Software}

Perangcangan software untuk billing playstation menggunakan Delphi XE8 dan MySql sebagai basis datanya.

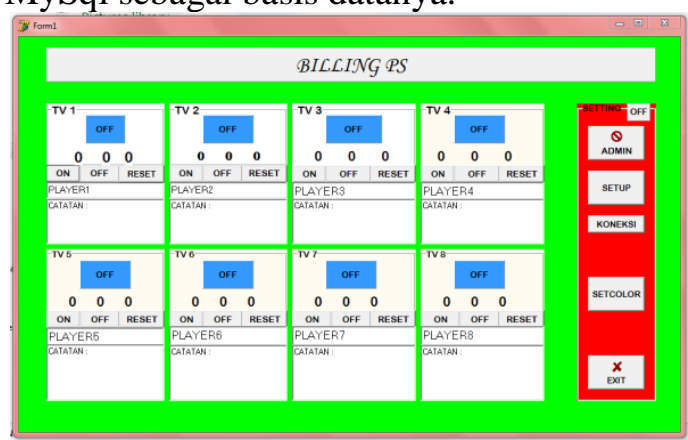

Gambar 5. Dashboard Billing Playstation

Pada dashboard billing playstation ada kolom konfigurasi dan kolom panel TV 1 sampai TV 8, masing-masing panel TV tersebut terdapat button On, button Off dan button Reset, label untuk perhitungan waktu bermain playstation serta terdapat 2 text box yang berfungsi untuk pengimputan nama pemain/rental playstation dan catatan yang diperlukan.

Pada kolom konfigurasi terdapat button admin, button setup, button konfigurasi, button setcolor dan button exit.

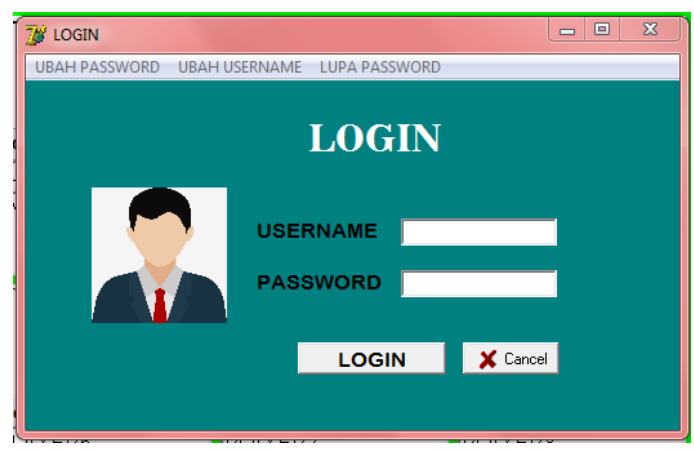

Gambar 6. Form Login

Untuk menampilkan form login dengan cara klik button admin pada form dashboard, form login berfungsi untuk mengubah konfigurasi harga billing playstation.

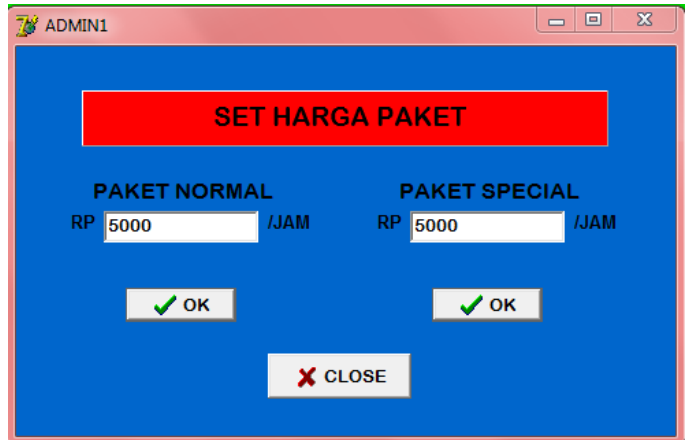

Gambar 7. Form Set harga paket rental playstation

Pada form set harga ini dibagi 2 paket yang berlaku yaitu paket normal dan special. Pada masing-masing paket dapat diatur harganya sesuai dengan keinginan ownernya.

\section{PENGUJIAN}

Setelah dilakukan perancangan hardware dan software, dilakukan penguji terhadap modul billing playstation. Pengujian ini dilakukan terhadap masing masing titik pengukuran di pin digital I/O serta pengukuran pada pin masing masing relay switch yang terkoneksi terhadap tegangan PLN. untuk pengukuran masingmasing pin di control dari software billing.

Berikut ini hasil pengukuran pada masing-masing pin.

Tabel 2. Pengukuran Modul Playstation

\begin{tabular}{|c|c|c|c|}
\hline No & Software & Modul Arduino & $\begin{array}{l}\text { Modul } \\
\text { Relay }\end{array}$ \\
\hline 1. & TV 1 On & Pin $4=12$ Volt & $\begin{array}{l}\text { Relay } 1= \\
220 \text { Volt }\end{array}$ \\
\hline 2. & TV 1 Off & Pin $4=0$ Volt & $\begin{array}{l}\text { Relay } 1= \\
0 \text { Volt }\end{array}$ \\
\hline 3. & TV 2 On & Pin $5=12$ Volt & $\begin{array}{l}\text { Relay } 2= \\
220 \text { Volt }\end{array}$ \\
\hline 4. & TV 2 Off & Pin $5=0$ Volt & $\begin{array}{l}\text { Relay } 2= \\
0 \text { Volt }\end{array}$ \\
\hline 5. & TV 3 On & Pin $6=12$ Volt & $\begin{array}{l}\text { Relay } 3= \\
220 \text { Volt }\end{array}$ \\
\hline 6. & TV 3 Off & Pin $6=0$ Volt & $\begin{array}{l}\text { Relay } 3= \\
0 \text { Volt }\end{array}$ \\
\hline 7. & TV 4 On & Pin $7=12$ Volt & $\begin{array}{l}\text { Relay 4= } \\
220 \text { Volt }\end{array}$ \\
\hline 8. & TV 4 Off & Pin $7=0$ Volt & $\begin{array}{l}\text { Relay } 4= \\
0 \text { Volt }\end{array}$ \\
\hline 9. & TV 5 On & Pin $8=12$ Volt & $\begin{array}{l}\text { Relay } 5= \\
220 \text { Volt }\end{array}$ \\
\hline 10. & TV 5 Off & Pin $8=0$ Volt & $\begin{array}{l}\text { Relay } 5= \\
0 \text { Volt }\end{array}$ \\
\hline
\end{tabular}




\begin{tabular}{|c|l|l|l|}
\hline 11. & TV 6 On & Pin 9=12 Volt & $\begin{array}{l}\text { Relay 6 }= \\
220 \text { Volt }\end{array}$ \\
\hline 12. & TV 6 Off & Pin 9 =0 Volt & $\begin{array}{l}\text { Relay 6 } \\
0 \text { Volt }\end{array}$ \\
\hline 13. & TV 7 On & Pin 10=12 Volt & $\begin{array}{l}\text { Relay } 7= \\
220 \text { Volt }\end{array}$ \\
\hline 14. & TV 7 Off & Pin 10=0 Volt & $\begin{array}{l}\text { Relay 7 }= \\
0 \text { Volt }\end{array}$ \\
\hline 15. & TV 8 On & Pin 11 =12 Volt & $\begin{array}{l}\text { Relay } 8= \\
220 \text { Volt }\end{array}$ \\
\hline 16. & TV 8 Off & Pin 11 =0 Volt & $\begin{array}{l}\text { Relay } 8= \\
0 \text { Volt }\end{array}$ \\
\hline
\end{tabular}

VII. DAFTAR PUSTAKA

[1] Zulhipni Reno Saputra, "Perancangan Smart Home berbasi Mikrokontroler Arduino," Jurnal Sigmata, vol. 4, no. 1, pp. 43-52, Oct. 2015.

[2] Zulhipni Reno Saputra, "Simulator Penghitung Jumlah Kendaraan Pada Pintu Masuk Dan Keluar Berbasis Arduino," Jurnal Sistem Komputer, vol. 2, no. 2, pp. 98-104, 2017.

\section{KESIMPULAN}

Kesimpulan yang didapat dari penelitian ini:

1. Modul billing playstation berfungsi sesuai kebutuhan.

2. Modul billing playstation ini hanya memuat 8 port playstation, sehingga tidak bisanya penambahan port playstation.

3. Aplikasi yang dibuat untuk billing playstation ini hanya untuk mencatat dan mengaktifkan port playstaion apabila konsumen ada pembelian makan serta minuman tidak tercatat pada nota rental playstationnya.

4. Berdasarkan hasil pengukuran yang dilakukan terhadap modul billing, setiap pin menghasilkan tegangan yang diharapkan.

\section{SARAN}

Adapun saran untuk penelitian lebih lanjut yaitu:

1. Modul billing playstation sebaiknya jumlah port untuk ditambah lagi, minimal jumlah portnya sebanyak 20 playstation.

2. Aplikasi billing sebaiknya ditambahkan poin of sale untuk cafe.

3. Modul billing playstation dikombinasikan sms gateway, sehinga owner dapat mengetahui pada waktu tersebut ada yang sedang rental playstation.

Zulhipni Reno Sapura, "Perancangan Monitoring Suhu Ruangan Menggunakan Arduino Berbasis Android Di PT. Tunggal Idaman Abdi Cabang Palembang," J. Teknol. Inf., vol. 8, no. 2, p. 37, 2016.

[4] Y. A. Badamasi, "The working principle of an Arduino," Proc. 11th Int. Conf. Electron. Comput. Comput. ICECCO 2014, 2014.

https://www.tokopedia.com/efgadge t/ modul-relay-8-channel-arduinospdt-5v-5-pin."

[6] A. Halim and S. Hasan, "Sistem Informasi Pengelolaan Uang Komite Menggunakan Borland Delphi 7 Pada Sma Negeri 5 Kota Ternate," IJIS - Indones. J. Inf. Syst., 2017.

[7] Karnadi, "Analisis Perancangan Sistem Informasi Akademi Pada SMP Muhammadyah 1 Palembang dengan Metode Waterfall," Jurnal Sigmata, vol. 4, no. 1, pp. 23-32, 2016. 